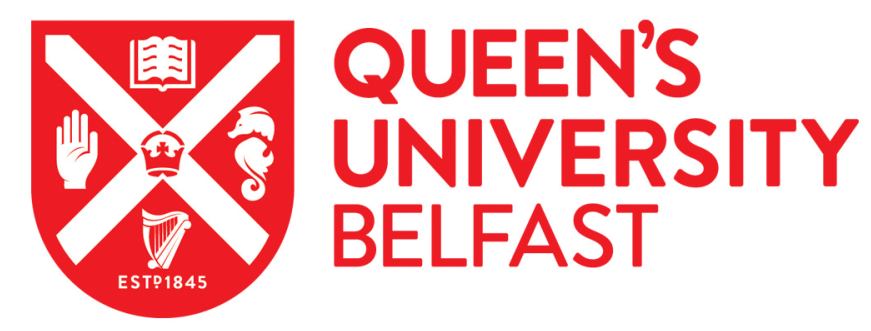

\title{
Understanding allied health practitioners' use of evidence-based assessments with children with cerebral palsy: A mixed methods study
}

O'Connor, B., Kerr, C., Shields, N., \& Imms, C. (2017). Understanding allied health practitioners' use of evidence-based assessments with children with cerebral palsy: A mixed methods study. Disability and Rehabilitation, 41(1), 53. https://doi.org/10.1080/09638288.2017.1373376

Published in:

Disability and Rehabilitation

Document Version:

Peer reviewed version

Queen's University Belfast - Research Portal:

Link to publication record in Queen's University Belfast Research Portal

Publisher rights

( 2017 Taylor and Francis This work is made available online in accordance with the publisher's policies. Please refer to any applicable terms of use of the publisher.

\section{General rights}

Copyright for the publications made accessible via the Queen's University Belfast Research Portal is retained by the author(s) and / or other copyright owners and it is a condition of accessing these publications that users recognise and abide by the legal requirements associated with these rights.

Take down policy

The Research Portal is Queen's institutional repository that provides access to Queen's research output. Every effort has been made to ensure that content in the Research Portal does not infringe any person's rights, or applicable UK laws. If you discover content in the Research Portal that you believe breaches copyright or violates any law, please contact openaccess@qub.ac.uk. 


\section{Manuscript Title}

Understanding allied health practitioners' use of evidence-based assessments for children with cerebral palsy: a mixed methods study.

\section{Running Head}

Assessment use in CP

\section{Article category}

Assessment procedures

\section{Authors}

Bridget O'Connor 1 Claire Kerr 2 Nora Shields 3, 4 Christine Imms 5

\section{Affiliations}

1 School of Allied Health, Australian Catholic University, Melbourne, Australia

2 School of Nursing and Midwifery, Queen's University Belfast, Belfast, United Kingdom

3 School of Allied Health, La Trobe University, Melbourne, Australia

4 Northern Health, Melbourne, Australia

5 Centre for Disability and Development Research, Australian Catholic University, Melbourne, Australia

\section{Corresponding Author}

Christine Imms

Locked Bag 4115, Fitzroy Victoria, Australia 3065

Tel: +61399533404

Fax: +61394171399

Email: christine.imms@acu.edu.au

\section{Declaration of Interest}

The authors state that they have no interests which might be perceived as posing a conflict or bias.

\section{Word count:}

Abstract: 201

Main text: 7851

Tables: 5 Boxes: 1 Figures: 3 


\section{Abstract}

Purpose Evidence-based assessments for children with cerebral palsy are not widely used by healthcare professionals in day-to-day practice. This study aimed to examine allied health practitioner experiences, perceptions and use of assessments for children with cerebral palsy.

Method A mixed methods study was conducted in two rehabilitation organisations. Three focus group interviews explored therapists' assessment experiences with data analysed using interpretive description. Assessment practices of therapists $(n=55)$ were assessed through self-report questionnaire and case-file audit of children with cerebral palsy $(n=44)$.

Results Emergent themes described therapists' motivation to use evidence-based assessments on a behavioural continuum - I don't; I can't; I try; I do; We do; influenced by assessment satisfaction, child and family collaboration, organisational expectation, research fit, and time dedication. Only two of fifteen audited assessments were documented in more than $50 \%$ of files. Use was higher where assessments positively connected therapists, children and parents, and use was organisationally endorsed. The Cultural Cone for evidence-based assessment behaviour was conceptualized.

Conclusion "Engagement in" assessment appears to require a conceptual shift by therapists and organisations to understanding assessment as part of, not an adjunct to, therapy. The Cultural Cone framework may assist therapists and services I designing strategies to promote evidence-based assessment behaviours.

\section{Keywords}

Assessment; cerebral palsy; knowledge translation; evidence based practice; allied health professional; behaviour change

\section{Implications for rehabilitation}

- Therapists' can reflect on where they are positioned on the "use continuum" in the Cultural Cone framework, and consider the contextual influences contained in this framework to understand their motivation to use evidence-based assessments.

- Routine use of evidenced-based assessments for children with cerebral palsy by allied health practitioners remains generally low and therapists and service organisations need to consider ways to increase use. 
- Where possible, therapists should choose assessment tools that fully engage children and families and themselves in the assessment process.

- The Cultural Cone framework may be used to assist therapists and organisations identify and design site specific strategies to increase evidence-based assessment use in day-to-day practice.

\section{Introduction}

Assessing children with cerebral palsy in a therapeutic context requires information to be gathered from a range of sources that can inform clinical decision-making and goal setting, and evaluate outcomes of therapy interventions. Over the past two decades many clinically relevant and psychometrically robust assessment tools have been developed for children with cerebral palsy [1-

3]. Use of these assessment tools is now considered integral to evidence-based [4-7] and collaborative decision-making $[2,8]$ in the field of childhood disability and rehabilitation $[3,9,10]$.

Within an evidence-based practice framework [11] findings from valid and reliable assessments are integrated with findings from informal methods of assessment, clinician and family expertise, and child and family aspirations, within the resources available and their context. Including evidencebased assessments in clinical practice has been promoted by educational and professional health bodies for many years. In spite of these efforts, adoption of the tools in day-to-day clinical practice has been slow [6,12-15], and their use in the field of cerebral palsy is no exception [3,16-18]. A recent systematic review of allied health practitioners use of evidence-based assessments for children with cerebral palsy, highlighted only a limited number of validated tools were used, and not in all practice settings [19].

Many studies have explored potential barriers and supports to the use of evidence-based assessments in clinical practice $[6,20,21]$. Barriers have been identified at multiple levelsorganization, practitioner, assessment tool and patient. Commonly perceived barriers include low levels of organizational commitment and support, diminished knowledge and confidence in tool selection and administration, and low levels of perceived value and "fit" of assessments to the clinical setting. Practical issues related to tool availability, cost and time are also reported as factors influencing use in the clinical setting [6].

To date, the effectiveness of knowledge translation interventions to increase and embed assessments into clinical practice has been inconsistent or modest [22,23]. A recent systematic review investigating the effectiveness of knowledge translation interventions to increase allied 
health practitioners' use of standardized assessments [22] reported only a few studies using interventions tailored to known barriers - instead, most studies rely on less effective traditional educational strategies [24]. Multifaceted [25] interventions tailored to identified barriers [26], across multiple levels $[6,27]$ are more likely to be effective in changing health professionals behaviours.

Clinical practice is complex and multiple factors are likely to interact to influence a clinicians' decision to use assessments $[28,29]$. Direct causal links between identified barriers to assessment use and eventual uptake of assessments cannot be assumed. Even when barriers are identified, it is not clear which barriers to target, their relative importance, and whether or not all barriers have been identified [29].

Effective knowledge translation also requires an in-depth understanding of behaviour and how to bring about optimal behaviour change for therapists working in complex clinical environments. Two theoretical frameworks can be considered in relation to changing practitioner behaviours; [30] motivational readiness for change based on the Trans-theoretical Model [31,32], and concepts of autonomous motivation founded on Self-Determination Theory. [33] The Trans-theoretical Model [31] describes how an individual moves towards initiating and sustaining a new behaviour through readiness-based stages of change: pre-contemplation, contemplation, preparation, action and maintenance. Action is preceded by a decisional balance point where a conscious decision is made to pursue goals around changing behaviour [34]. Self-Determination theory describes motivation states and their accompanying degrees of "ownership" of the intent to act $[30,35]$. When amotivated, intent is absent or lacking, the activity is not valued, and low levels of competence and autonomy, or self-determination are often present. Extrinsically motivated behaviours satisfy external rewards or demands and carry low degrees of autonomy and "ownership". More autonomous forms of motivation see increasing degrees of internalized value and ownership of the behaviour and diminished external regulation. When intrinsically motivated, the behaviour is accompanied by high degrees of competence and autonomy and pursued for its inherent value, satisfaction and enjoyment. A growing evidence base exists for behaviour change interventions derived from these theoretical frameworks e.g., Health Coaching [34] and Cognitive Orientation to daily Occupational Performance [36].

Understanding the social and contextual influences on therapists' decision to use, or not to use, evidence-based assessments is essential to enable design of more effective behavioural change interventions to increase evidence-based assessment use for children with cerebral palsy 
$[3,19,22,23,26,28,29,37]$.The aim of this study therefore was to develop an in-depth understanding of allied health practitioners' real world practices; their experiences, perceptions and use of standardized assessments for children with cerebral palsy in different clinical contexts. The social and practical dimensions of this phenomenon called for a multi-dimensional research paradigm that could describe what tools were used to what extent, the social and cultural context for use (when, where and how) and identify potential interacting factors - both external and internal to the health professional - that could help explain why practitioners may or may not use assessment tools in practice. A mixed methods research approach [38], that integrates quantitative (positivist) and qualitative (interpretivist) theoretical perspectives, was therefore chosen.

Specifically we wanted to determine;

a) What were allied health practitioners' experiences and perceptions of using of evidence-based assessments in clinical practice?

b) To what extent were evidence-based assessments used by allied health practitioners for children with cerebral palsy?

c) Are differences in allied health practitioners assessment experiences reflected in practitioners' use of assessments in different organisational contexts?

\section{METHODS}

This study formed part of a larger project [39] evaluating the effectiveness of a multifaceted knowledge translation intervention to improve allied health practitioners' research implementation behaviours. The larger study was conducted in five Australian based organisations that provided community-based rehabilitation services to children with cerebral palsy.

\section{Study Design}

A concurrent, qualitatively-driven [40] mixed methods study design [41] was adopted that enabled between-method triangulation, elaboration of results from each method and enhanced contextual validity [38]. Although standardized instruments, (e.g. Alberta Context Tool [42], Barriers and Facilitators Assessment Instrument [43]) have been developed to assess organisational contextual factors, these tools are in their early stages of development and are not yet transferable between contexts [44] nor psychometrically robust [45], and thus were not used.

\section{Study Setting}

The study focussed on two of the five organisations participating in the larger study; Organisation A and Organisation B. Both organisations were situated within the same Australian state. Organisation 
A, a large service, was based in a metropolitan city (population of 4.4 million) and provided schoolbased and early intervention therapy services to children and adults with a wide range of disabilities. Organisation B, a small service, was situated in a regional city (population of 225,000 ) and provided centre-based and outreach services to children with cerebral palsy. Sites were chosen for their contrasting size and locations, common state legislature and convenience. Organisational characteristics such as size and number of sites, profiles of children attending the service, staffing and geographical location, were gathered using a study-specific Organisational Profile questionnaire completed by each organisation. The characteristics of each setting are shown in table 1.

\section{[Insert table 1 here]}

\section{Study participants and recruitment}

Eligible participants from the two organisations included i) allied health practitioners: physiotherapists, occupational therapists and speech pathologists who worked with, or had the potential to work with, children with cerebral palsy, and ii) children aged 3 to 18 years diagnosed with cerebral palsy and their families. Organisation-specific recruitment strategies included on-site information sessions held for staff and families by the research team, word-of-mouth advertising and through distribution of posters, newsletters and email advertisements. In addition, allied health practitioners received a letter containing project information and an invitation to participate. Voluntary, written informed consent was obtained to complete two questionnaires and to participate in an audio-recorded focus group. Families, whose children with cerebral palsy received therapy services from the participating organisations, were provided with information about the study via the research team or the child's therapist. Participant families provided voluntary written consent to collect and securely store relevant clinical information from their child's file. Children with cerebral palsy, enrolled in the first phase of the larger study before $22^{\text {nd }}$ January 2014 , were included in the current study.

\section{Ethics}

Ethical approval was obtained from the Australian Catholic University Human Research Ethics Committee (2012 309V), the Department of Education and Early Childhood Development (2013_001962), and the Cerebral Palsy Alliance Human Research Ethics Committee (2013-04-02) as part of the larger study; CP Check Up: providing the best service at the best time.

\section{Data collected}


Allied health practitioners experiences and perceptions of evidence-based assessment use were obtained through focus group interviews. The extent to which evidence-based assessments were used by allied health practitioners (frequency of use) was assessed using two sources a) the Evidence Based Practice Competencies Questionnaire-Cerebral Palsy - a psychometrically evaluated selfreport measure of allied health practitioners evidence-based practice behaviours (test-retest reliability ICC $=.94)[46]$, and b) case-file audit. A second questionnaire (Supports and Barriers Questionnaire [47]) was used to ascertain allied health practitioners perceptions of known factors [48] influencing the routine use of assessment tools. Data reported here were collected during the baseline period of the larger project. Questionnaires were administered to allied health practitioner participants during scheduled in-service days at each organisation.

1) Focus groups were held at each site; two at Organisation A, one at Organisation B. Focus groups were guided by the same experienced and independent moderator using an interview topic guide developed by the investigators (see Box 1). Due to the small number of therapists in Organisation B, individual details of focus group participants were not recorded to protect individual therapist identity. Between four and seven allied health practitioners participated in each group with all therapy disciplines represented. Member checking was instigated periodically throughout each focus group to confirm facilitator understanding and enhance confirmability of the data. Interviews were audiorecorded and lasted 1 to 1.5 hours. Recorded data were transcribed verbatim by a professional transcription service and imported into QSR NVivo version 10 for data management.

2) The following data were extracted: participant information (profession, years of clinical experience, postgraduate qualifications, continuing education and level of clinical expertise), and Evidence Based Practice Competencies Questionnaire-Cerebral Palsy items which assessed therapists self-rated frequency of use $(0-5 \%, 6-24 \%, 25-49 \%, 50-74 \%, 75-100 \%$ of the time) of three validated assessments for children with cerebral palsy: (1) functional classification tools (Gross Motor Function Classification System, Manual Abilities Classification System and Communication Function Classification System), (2) Canadian Occupational Performance Measure and (3) Goal Attainment Scaling. These individualised, non-discipline specific tools are well-known, freely available, and recommended for children with cerebral palsy [10].

3) Children's case-files were audited during March-April 2013. Audit 'data capture periods' were selected to reflect best practice in routine surveillance for children with cerebral palsy: a 6 month 
period for children under six years of age, and 12-months data capture period for children six years or older [49]. The audit period preceded implementation of the larger study to avoid contamination. The following case-file data were extracted: age, gender, cerebral palsy type and distribution, and the presence or absence of results from 15 validated assessments. Decision-making by the research team in relation to which assessments to include in the audit was based on; whether or not they were validated for children with cerebral palsy; their importance in surveillance of progressive musculoskeletal deformity; and generic availability and applicability across types, age, severity of cerebral palsy, and important ICF-CY [50] domains of functioning [51]. A data collection form was developed for the case-file audit and data were extracted by an independent research assistant and the primary author.

4) Supports and Barriers Questionnaire [47], used an 11-point Likert Scale $(-5$ to +5$)$ to ascertain allied health practitioners' perceived extent to which five factors; organisational structures and resources, therapists, assessment tools and children and families, were perceived as barriers to routine assessment tool use.

\section{Qualitative data analysis}

Focus group data transcripts were analysed inductively using an interpretive description approach $[52,53]$. Interpretive description focuses on generating new knowledge through understanding "complex experiential clinical phenomena within nursing and other health disciplines concerned with applied health knowledge or questions [from the field]" [54, p27]. It aims to make sense of the variability that accompanies practice in the real world of health care [53]. Themes and patterns within subjective perceptions of a clinical phenomenon are captured, interpreted, conceptualized and presented in new ways that can inform clinical understanding $[53,54]$.

Initial immersion in the combined focus group data by the first author generated broad categories reflecting areas of therapist interaction with evidence-based assessments. Categories were cross checked for authenticity by the co-authors. Textual data were further interrogated by the first author for thematic relationships, patterns and linkages through an iterative process of labelling and conceptual development. A reflective journal was kept with questions posed in relation to the data during thematic development such as: "In what practical and social contexts are assessment tools used? How do therapists view and decide to use standardized assessments? How do therapists use evidence-based assessments? What social, intellectual or emotional interactions accompany therapists' use of assessments?" Emergent sub-themes were condensed into overarching themes 
that captured the timbre and context of therapists' interactions with assessment tools in the clinical setting.

\section{Quantitative data analysis}

Descriptive data were analysed using frequency counts and descriptive statistics. Allied health practitioners were categorized as "High-user", "Moderate-user" or "Low-user" on the basis of selfreported use of the three assessments included in the Evidence Based Practice Competencies Questionnaire-Cerebral Palsy. High-users were allied health practitioners who reported using functional classification tools $A N D$ an individualized tool (Canadian Occupational Performance Measure, or Goal Attainment Scaling), more than $50 \%$ of the time. A moderate-user used some tools to some extent; i.e., functional classification tools $O R$ an individualized tool more than $25 \%$ of the time but did not meet high-user criteria. Low-users did not use any tools to any extent; i.e., functional classification tools $A N D$ individualized tool less than $25 \%$ of the time.

Individual child case-file audit data were converted to a Use Index Score, calculated as: (number of assessments completed/total number of assessments possible) $\times 100$. A Use Index Score of 0\% indicated no audited assessments were completed; a Use Index Score of $100 \%$ indicated all audited assessments were used. The Use Index Score enabled comparison of the number of assessments documented per child during the audit period._Responses to the Supports and Barriers Questionnaire were analysed using descriptive statistics, with Likert scores of less than -1 categorized as a "Barrier", "Ambivalent" if between -1 and +1 , or a "Support" if greater than +1 .

Data synthesis occurred in three phases. Initially, qualitative findings were examined by the primary author, looking for potential relationships across themes and sub-themes. Secondly, a model, illustrating the interactive elements and processes inherent in allied health practitioners' assessment behaviours, was developed and reviewed for authenticity by the co-authors. This model was considered in relation to, and then situated within, current theories for understanding motivation and behaviour change. Finally, analysed quantitative data were merged with the qualitatively derived model and considered in relation to each organisation; the experiences and perceived barriers (focus group and questionnaire data), the amount and types of assessments used by therapists (self-report and audit data), and organisational, therapist and child characteristics.

\section{RESULTS}

Participant characteristics 
Of 73 eligible allied health practitioners from both organisations, 55 (75\%) completed both questionnaires (see table 2). Sixteen allied health practitioners participated in three focus groups; nine from Organisation A and seven from Organisation B. Proportionally, Organisation A had fewer physiotherapists and a greater spread in staff experience than Organisation B. The characteristics of the children with cerebral palsy are displayed in table 3. Overall, the children with cerebral palsy from Organisation B were younger (pre-school age) with higher levels of functional mobility than those from Organisation A.

[Insert table 2 here] [Insert table 3 here]

Allied health practitioner experiences and perceptions of using evidence-based assessments Focus group discussions centred on how allied health practitioners experienced and used standardized assessments in their practice. The following key themes and sub-themes emerged from the data.

\section{Assessment Tool Use}

Motivation and Accessibility: I don't, I can't, I try, I do, We do.

Within the 'Assessment Tool Use' category therapists reported their rationale, approach and subsequent use of evidence-based assessments. Responses ranged from those who reported not using tools (I don't) to those that did (I do and We do). Tool use related to "motivation" and tool "accessibility".

"I don't" therapists could not justify using standardized assessments, instead preferring to draw on informal methods.

"It's not applicable to assess every single child due to cognition, due to various different reasons.... unless there's actually relevance for doing an assessment I wouldn't."(Organisation A)

"I can' $t$ " therapists were unable to use standardized assessments due to constraints in availability; tools were either unavailable in their setting or they perceived that tools had not yet been developed for the children with complex needs on their caseload. 
"With a lot of the students [children with CP] here, trying to do some of the more formalised assessments our students don't always fit into the categories or the assessments that we have available."(Organisation A)

Other therapists recognized the need for using standardized assessments. "I try" therapists actively pursued ways to use assessments in spite of identified constraints.

"It was like, well, how do I assess this girl who's come on a boat from Christmas Island? What do I use? Like I asked around and we did the GMFM on her but that was my first assessment tool and it was driven by me wanting to get a baseline of something from somewhere."(Organisation A)

"I do" therapists adopted an individualised and unplanned approach in their settings where assessment use did not appear embedded.

"Whether it's just a Six Minute Walk test or a Timed Up and Go there's always something I can use somewhere."(Organisation A)

"We do" therapists reported using selected tools routinely, in a way that was collaborative, systematic and planned.

"That's built into our practice for every child - we do GAS [Goal Attainment Scaling] every term."(Organisation B)

\section{Assessment Activity}

\section{Satisfaction: Value, Enjoyment, Authenticity}

Through therapists' descriptions of the "activity of using assessment tools" it was possible to ascertain a sense of satisfaction with assessment that was linked to concepts of value, enjoyment and authenticity. Using tools was valued highly when additional insights and foci for interventions were provided, and the tool enabled collaboration with the child, family and the team about life's real needs. There was a deep sense of satisfaction in capturing a child's progress.

"I love that we're now using the COPM [Canadian Occupational Performance Measure] prior to them choosing a GAS [Goal Attainment Scaling] goal. I love that it gives you this holistic view and as there are changes we're like, yep this is what we're talking about."(Organisation B) 
"It keeps you in focus too... because you get all sorts of other ideas and you can go all over the place but it's like these are the two that I need to measure. So it keeps me really focused."(Organisation B)

For other therapists, findings from assessment tools did not add further value to the information they gathered through informal methods of assessment.

"I find there is so much value in discussions and informal observation, more so sometimes than using my standardised assessments."(Organisation A)

When the tool was fun to use adjustments were made to overcome practical challenges associated with use. Satisfaction however was influenced by tools being too complex and tools could be quite stressful for therapists to use.

"For my Assisting Hand Assessment -I did six videos before the group and six videos afterwards. You know, it's great fun when you do the assessment but I've now got eight videos to score and I'm just trying to drip away, like I need cancellations."(Organisation B)

"I still use it to guide my practice, but the complexity and availability, like I did my research on one of the assessment tools, and I'm still confused about it a lot of the time. I mean, and I did it for a year."(Organisation $A)$

"It's still a really complex tool, like writing GAS [Goal Attainment Scaling] goals is hard and you really have to think about it - you can never jot down a GAS goal - I can't."(Organisation B)

"Writing GAS [Goal Attainment Scaling] goals is stressful and difficult."(Organisation B)

Therapists valued tools that were authentic; that is they accurately reflected a child's capabilities within real-world contexts and could be widely applied.

"I think ones that you can do with a variety of kids, not just kids that are willing to sit down at a table and do task after task after task... But can you employ it in a more natural way and actually feel like you're capturing an accurate picture of the kid."(Organisation B)

"I'm not going to use that [Peabody assessment] anymore because it's just not really useful for me in that situation, as in it's probably a useful tool if you work with children who have perfect cognition and language, but I don't have any of these [children] on my caseload."(Organisation B) 


\section{Research}

\section{Congruence: Critique, Affinity}

Evidence-based assessment was discussed within the context of therapists' interaction with research and evidence-based practice. Therapists grappled with "finding a fit", or congruence, between research, the child and family and their own personal intervention preferences. Therapists with a strong affinity for research endeavoured to find evidence to endorse their practice, but were very careful and critical in their application of this evidence to individual children and families. Using evidence-based assessments was seen as necessary to evaluate the impact of interventions.

"The biggest concern to me is when someone says Green Light bi-manual training, fantastic, so you send your kid off for bi-manual training and it's a disaster because it's a Green Light so they just do it, but they're not measuring, they're not thinking, they're not applying it to the right child."(Organisation B)

"It's important to us as an organisation that we do monitor what we're doing and that we are measuring what we're doing." (Organisation B)

Other therapists talked of the tension they felt between evidence, and their personal preference for practices they enjoyed using and that they felt were effective. Therapists seeking to align evidence with the child and family's needs, referred to using objective methods of outcome measurement to support their practice. In contrast, therapists' with less affinity for research-informed practice preferred to adopt interventions based on personal preference and talked of "seeing" and "feeling" the benefits of their interventions.

"I can see the benefits of this, but the research isn't matching up. I really want to use it, but my senior is going to tell me not to use it, but I can see the clinical benefits of it."(Organisation A)

"I know a lot of the stuff that I personally enjoy using, that I feel works for the kids from here isn't rated very highly."(Organisation A)

\section{Families and children}

\section{Collaboration: Understanding and Involvement}

In the context of families and children, collaboration was perceived to be influenced by both family and therapist understanding and involvement in the assessment process. Therapists perceived 
families liked assessment but that parents' often did not have sufficient information. Therapists found it difficult to explain assessment results in ways that families could understand.

"I think families like assessment. It's just they don't necessarily know that they can ask for it, and what we can provide."(Organisation A)

"You write up the results to explain to the parents, what this assessment means, what's involved in it ....you give them the report, it's very difficult for them to understand the interpretation, the language."(Organisation A)

Some therapists did not see a role for standardized assessments to inform goal setting with families.

"As a key worker in our service, it's not about actually sitting down and doing an assessment. You work at the level that they're at and set goals."(Organisation A)

In contrast, other therapists perceived the use of assessment tools as a powerful means of involving and enhancing collaboration with families. In these instances families were also seen as informed and receptive to assessment.

"I would have said we did it really well, we listened to families and did the goals, but since we've done the COPM [Canadian Occupational Performance Measure] it's just taken on a whole new level."(Organisation B)

"Reflection is a really positive thing, to have that time to reflect and discuss with the parents and the families and the children what your goal is going to be, what their goal is, but then to actually write that [Goal Attainment Scaling goal] takes a lot of reflection and it helps you capture what you want to. It guides you there."(Organisation B)

"We've got families on board, you know, it's all there ready for the taking really."(Organisation B)

\section{Organisational setting}

\section{Expectation: Opportunity, Encouragement, Systems}

Therapists perceived varying levels of expectation to use formalised assessments within their organisation. This was influenced by factors related to opportunity, encouragement and systems. Structural processes and service delivery methods directly affected therapists' opportunity to use 
formalised assessments. In the school setting, therapists found it difficult to access children and families for individualised assessment and goal setting. School therapy services were focussed on providing overall classroom support, with therapists' input guided by day-to-day observations rather than individualised assessment. Education goals were perceived as different from therapy goals.

“...here we don't tend to do the formalised assessments. It's more observation, informal I guess, the goals aren't really made - they're more around education. They're not traditional therapy goals that I'm used to because we're not putting formal interventions into place."(Organisation A)

"We don't do one-on-one. I don't say Joe Blogs has got this or we need to work on that. I haven't got the capacity to do that. I'm supporting the classroom."(Organisation A)

"When I first started we did a lot more formal kind of gross motor and range of motion... we had more specific key goals, physio goals and speech goals ...but then the school changed their reporting system and so we had to fit into that. The school management completely changed as well and so that completely changed what their priorities were. It's hard to work in an environment where you're still trying to do therapy but it's not therapy. "(Organisation A)

Similarly, the dual role of caseworker and therapist in the key worker service delivery model, created a tension for therapists between the professional expectation to use assessments and limited capacity and expectation of use within the organisation's service delivery model. Perceived opportunity to shape the therapy service within the organisation also varied.

"That's probably one of the constraints in the key worker model that you may never see - you can spend five years with a family and you're just really the consistent person that comes into the home. You become the person that families vent all their life stuff to. I would say about $60: 40,60 \%$ around the case manager and then $40 \%$ you're probably like a speechie."(Organisation A)

Expectation to use evidence-based assessments was strongly influenced by the encouragement and perceived value of assessment by management. Where use was actively promoted by management, therapists reported assessment use as a presumed and unquestioned part of practice. Goal setting was viewed as a collaborative process between family and therapist, informed by assessment. When positively encouraged, therapists felt compelled to meet the organisation's expectation to use assessments, with a sense of guilt prevailing if this expectation was not met. 
"It's really nice because there's that backup because our manager goes, 'Now I've looked at all your GAS [Goal Attainment Scaling] goals and that's good.' So that accountability."(Organisation B)

"You're really motivated to get them [Canadian Occupational Performance Measures] done and you feel really bad when you don't."(Organisation B)

"Outcome measures are just built in...you don't have a choice - it's just what you do."(Organisation B)

In contrast, other therapists in described being actively discouraged and questioned in their use of formalized assessments. Therapists perceived that standardised assessment was viewed by their organisation as unrelated to family centred practice and goal setting, and therefore unnecessary.

"For where I work- there kind of needs to be a purpose. We're sort of told, unless the family requests an assessment what's the point, like what are you going to use that information for? ...you're trying to be guided by the family's goals." (Organisation A)

Therapists reported on the systems in place to support the use of formalized assessment. Some settings had a planned schedule to ensure assessments were completed. In other settings assessments were performed on an ad hoc basis in spite of therapists' desire for a systematic approach.

"In the first two weeks, we all went in pairs and visited kids. We did the COPM [Canadian Occupational Performance Measure] in the home with two of us. It was a pretty full on couple of weeks, but it's made a difference."(Organisation B)

“We haven't had that [Dysphagia Severity Scale] and I think it's something that has been needed because no one standardly does the same practice."(Organisation A)

Participant: We are getting better at it- but we do it as a, oh, hang on, it's about time...

Participant: I do agree they [assessments] should be regular.

Participant: Yeah, but there's some [children] that just drop off the radar.

Participant: It's three years, and they haven't been reviewed.

Participant: Well they are reviewed but we don't do a formal assessment. (Discussion thread between Organisation A participants) 


\section{Use of time}

\section{Availability and Dedication: Not the time, If time, Making time.}

Therapists across all settings reported limited time for activities related to using formalized assessments. Therapists varied however in how they dedicated time to assessment activities. Therapists reported "making time" by opportunistically squeezing in assessment related tasks. .

"I've got eight videos to score and I'm just trying to drip away, like I need cancellations. The videos are done so it's just a matter of getting the scores done. But trying to fit them in is hard."(Organisation B)

Others reported assessment activity as a low priority and doing assessments only "if time" was available. Others felt there was "not the time". They were either not able to, or not prepared to, allocate time to evidence-based assessment activities, and that these activities were unlikely to happen at any time.

"In a setting like this, we don't have the time often to do formalised assessments-other things get prioritised."(Organisation A)

"I think we do value it [research], but yes, it's the same thing as for using standardised assessments, I sort of go, I don't have time to do that."(Organisation A)

Frequency of evidence-based assessment use

Actual and self-reported use of assessment tools are shown in table 4. The median Use Index Score was $13 \%$ in Organisation A and $20 \%$ in Organisation B. Two of the 15 tools audited were documented in more than $50 \%$ of children's files. Collectively, $16 / 55(29 \%)$ of allied health practitioners reported using classification tools (Gross Motor Function Classification System, Manual Abilities Classification System or Communication Function Classification System), 6/55(11\%) used the Canadian Occupational Performance Measure and 8/55(15\%) used the Goal Attainment Scaling, more than $50 \%$ of the time. Overall, higher levels of assessment use were reported in Organisation B; 5 of the 8 allied health practitioners (63\%) in Organisations B reported using at least one of the tools more than $50 \%$ of the time compared to $11 / 47$ (23\%) of allied health practitioners from Organisation A.

[Insert table 4 here]

Perceived barriers and supports for evidence-based assessment use 
High, medium and low-user ratings of the extent to which organisational structures and resources; therapy colleagues; children and families; and assessment tools, acted as a support or barrier to routine assessment tool use are shown in table 5. Therapy colleagues were not viewed as a barrier to use (i.e. a support or neutral). High-users rated all items as supportive to some extent. Low and medium-users rated items similarly although approximately one third rated organisational structures and resources as barriers to some extent.

[Insert table 5 here]:

SYNTHESISING THE FINDINGS: The Cultural Cone framework for evidence-based assessment behaviour.

The analysed qualitative data informed the development of a conceptual framework- the Cultural Cone - that describes the salient elements and relational processes that interact to influence a particular behaviour: in this instance, allied health practitioners' use of evidence-based assessments. We propose the Cultural Cone to visually represent the dynamic interplay between unique (but not always explicit) content and context specific processes that support an individual's beliefs, emotions and actions, at any point in time. It is unique to the setting, never exactly replicable, although similarities in component processes are likely to exist across settings.

Our "Cultural Cone" for evidence-based assessment behaviour, seen in figure 1, is characterised by the central behavioural element in focus, that of "Assessment Tool Use", that emerges from the interactions between it and the remaining elements, arranged as five segments of the cone. The overarching concept "Assessment as Therapy" transpires when all relational processes interact at the highest level; the point where assessment and therapy are coupled and assessment is conceptually and practically integrated as therapy. "We do" therapists, situated towards the top of the cone, embed evidence-based assessments in therapy, whereas "I don' $t$ " and "I can' $t$ " therapists conceptually de-couple assessment and therapy. Evidence-based assessments may be used but are not viewed as inherently "therapeutic". "I try" and "I do" therapists' may view standardized assessment similarly to "We do" therapists i.e. assessment and therapy are coupled, but practically assessment is unable to be or has not yet been embedded in therapy.

Using the theoretical frameworks of the Trans-theoretical Model [31,32] and Self-determination theory [33] we can interpret the I don't, I can't, I try, I do, and We do, findings of the Cultural Cone. Levels of motivation and use equated broadly to therapists readiness to change. "I don't" therapists 
could be considered at the pre-contemplative stage; "I can' $t$ " therapists are contemplating use but not acting, while "I try" therapists are hovering on the decision point of action; ready to act, but may be heavily influenced by their situation [34]. "I do" therapists use standardized assessments when individual circumstances allow, however use is not embedded into individual or team practice. "We $d o$ " therapists in contrast, collectively embed standardized assessment into day-to-day clinical practice. Use is maintained over time across the organisation, and assessment use is organisationally endorsed. Within self-determination theory [35] "I don't" therapists may be amotivated with little interest in formalized assessment. "I can't" therapists may be largely motivated by external factors while "I try" and "I do" therapists, who may highly value assessment, are still influenced by external factors - such as professional and organisational expectation. "We do" therapists may be both intrinsically and extrinsically motivated with high degrees of autonomy, with assessment pursued largely for its inherent value and enjoyment.

[Insert figure 1 about here- see below for caption]

Both qualitative data and quantitative data were combined to determine if therapists' experiences of assessment, as represented in the Cultural Cone model, reflected therapists use of assessments in different settings. This enabled a representational "Cultural Cone for evidence-based assessment behaviour" to be generated for each organisation (see figures $2 a$ and $2 b$ ). Textual data from Organisation A fell predominantly into the categories of I don't, I can't, I try, and to a lesser extent, I do. In contrast, all "We do" textual data originated from Organisation B. Organisational processes were described and perceived more strongly as barriers to assessment use in Organisation A. Similarly opportunities for family collaboration through assessment, time dedication, research and assessment fit, and satisfaction with assessment were described less positively overall in Organisation A. The frequency of assessment use by both organisations during the case-file audit period was low overall; however, differences in amount of use existed between settings. Organisation B's higher level of assessment use was consistent with the higher level use "We do" category of the Cultural Cone framework. Conversely, the lower level of assessment use in Organisation A was accompanied by lower level use categories in the Cultural Cone.

The "Cultural Cone for evidence-based assessment behaviour" for each organisation also needs to be considered in relation to organisational, therapist and child characteristics. All therapists in the smaller organisation, Organisation B, had intermediate or greater levels of expertise, and managed a cerebral palsy specific caseload within a multi-disciplinary service delivery model. In contrast over 
one quarter of practitioners in Organisation A reported themselves as novice practitioners with less than 5 years of experience in the disability sector. Therapists from Organisation A managed a mixed caseload of children that included a higher proportion of children with cerebral palsy classified Gross Motor Function Classification System IV or V within either a trans-disciplinary or school-based model of service delivery.

[Insert figure $2 \mathrm{a}$ and figure $2 \mathrm{~b}$ about here, side by side if possible- see below for captions]

\section{DISCUSSION}

The Cultural Cone framework for evidence-based assessment behaviour provides a new framework for conceptualizing allied health practitioners' use of evidence-based assessments for children with cerebral palsy in paediatric community rehabilitation settings. The framework illustrates the salient cultural ingredients that interact to influence the evolution of allied health practitioners' readiness and autonomous motivation to use evidence-based assessments within a clinical setting. These process interactions - across assessment activity, the child and family, organisational setting, research and time - culminate in evidence-based assessment use on a behavioural continuum of - I don't; I can't; I try; I do; We do. Motivation to use evidence-based assessments was higher when therapists, children and parents were able to connect positively through using assessment tools, and use was endorsed and supported by the organisation. Therapists were both intrinsically and extrinsically motivated to use assessments. Where use was well established, assessment was viewed positively and positioned practically and conceptually as "therapeutic", rather than as separate or optional. Consistent with the findings from a recent systematic review [19], use of individual tools in two Australian community settings was low overall, with gross motor function remaining the primary focus of tools used frequently. Differences in assessment use between settings however can be further understood and uniquely represented through the Cultural Cone. This may provide a meaningful framework to design organisational, practitioner and family focused knowledge translation interventions aimed at increasing evidence-based assessment use.

This study suggests the process of "engaging with" assessment arises from the co-dependent interaction between the therapist, the assessment tool, the assessment activity itself, research, the child and family, the organisational setting and time. This is consistent with the idea proposed by Bright (2015) [56] that engagement in healthcare is a "co-constructed process and state" where a connection gradually develops between the client and the provider that enables both to become active, committed and invested collaborators in healthcare. The state of "engaged in" evidence- 
based assessment occurs when therapist, child and family believe in, enjoy and dedicate time to the evidence-based assessment process. Conceptually and practically evidence-based assessment becomes part of, not an adjunct to, therapy. For assessment to become embedded in day-to-day practice a conceptual shift by the organisation, therapists, and families, needs to occur. When assessment use was not perceived as therapeutically beneficial overall, formalized assessment was fitted-in only "if time" and not at the expense of "doing therapy" [57]. While limited time may have contributed to low levels of use overall in this study, it does not account for all differences. When the assessment process was understood by all parties - organisation, therapists and families - to add value to therapy, then time was 'found' to use evidence-based assessments.

Assessment use was situation dependent. In our study, where systems and supports existed for using assessment tools, experiences were recounted using the collective pronoun "We do". Where organisational support for use was absent, individual therapists found it difficult to use assessments consistently. Individual therapists were left to decide if, when and what tools to use, and were unsure about how assessment would be perceived by families. Even autonomously motivated therapists found it difficult to consistently implement assessments without wider organisational support. Therapists and families from the smaller single site service, predominantly for children with cerebral palsy, appeared to fit more closely with the definition of being "engaged-in" evidencebased assessment. In contrast, therapists in the larger multi-site organisation servicing a mixed caseload of children within different service models were either in the process of "engaging with" or, in some instances "dis-engaged with" evidence-based assessment. This suggests that, in addition to organisational support, service delivery model and caseload breadth may also influence therapists' use of evidence-based assessments.

Central to paediatric therapy practice is the formation of a positive therapeutic relationship between the child, parent and therapist $[3,55]$. Currently this relationship is situated within best-practice frameworks of family-centred and evidence-based care [58]: Therapists endeavour to develop a clear understanding of the child and family's priorities alongside skilful selection, administration and sharing of assessment findings to promote collaborative goal setting, intervention planning and objective measurement of meaningful outcomes to the child and family [2]. Inclusion of formalized assessment is integral to the care process but appears contingent on both parental and child understanding and involvement, as well as therapists' ability and confidence to use and discuss findings from the assessment tool in a way that enhances, rather than jeopardizes, their relationship with the child and family. 
The clinical utility of existing and future assessment tools also requires particular consideration in relation to their influence on the therapist-child-parent relationship. Therapists reported that using tools was deeply satisfying when the assessment tool was uncomplicated, the process was fun and engaging for themselves and the child, and the tool could easily capture meaningful changes in the child. Fun and engagement for both child and therapist during a tool's administration is also important for obtaining a child's optimal performance [59]. The recently developed Challenge tool [59], that has explicitly incorporated fun, engagement and children's opinions during development [60], has been reported to be perceived by children and parents to engender a sense of achievement and pride in the child (V.Wright personal communication 16/12/2016). Other recently developed tools e.g. DISABKIDS Chronic Generic Measure [61] and Perceived Efficacy and Goal Setting [62], contain child and parent friendly visuals and colour schemes that may facilitate discussion and improve motivation and communication between the therapist and child [61]. An assessment tool's capacity to engage, promote communication, efficiently assess and easily document changes relevant to everyday life may be important tool characteristics needed to support the therapistchild-parent relationship, and be adopted in practice. Including clinical end-users early in the tool design phase, particularly children, families and therapists from across different clinical, geographical and cultural settings, may be critical for a tool's adoption in the longer term.

The importance and benefits of using evidence-based assessments has been widely documented $[2,8,9,63,64]$. However, the low levels of use and engagement in formalized assessment found in this study suggests many therapists and their organisations are yet to be convinced of their direct benefit or value to themselves or the child and family [65]. Studies evaluating the immediate and long term benefits, non-benefits or harms of using standardized assessments with children and families are sparse $[8,2166,67]$. Routine surveillance programmes (incorporating standardised assessments) for children with cerebral palsy have demonstrated improved bio-mechanical and pain outcomes $[49,68]$. Individualized client-centred tools such as DISABKIDS Chronic Generic Measure and Canadian Occupational Performance Measure have been associated with increased motivation with activity-focused interventions and improved therapy practice $[63,61]$. Further research however, is warranted to demonstrate if inclusion of appropriately selected evidence-based assessment tools adds more to enablement of the child and family, than informal and observational assessments only. 


\section{Implications for practice}

A multi-faceted approach, combining wider organisational support systems with individualised evidence-based behaviour change techniques to support therapists' use of selected tools, is recommended. The Cultural Cone provides a framework for therapists and organisations to selfassess use behaviours, and review the relative strengths of modifiable elements influencing use. The Cultural Cone provides a potential basis for choosing practical and behavioural interventions to increase use. This framework proposes interventions that specifically address individual therapists' motivation through the lens of the therapist-parent-child relationship within a supportive organisational context. In practice, interventions grounded in motivational interviewing and selfdetermination theory [69] that support therapists autonomous motivation may be beneficial $[26,69$ 72]. Individual goal identification and ownership, developing "just right" challenges for increasing assessment use within the practice setting are needed. This approach aligns with recommendations for tailored knowledge translation interventions to bring about change in clinical practice [26]. Individualized support on how to involve families and children in the assessment process using carefully chosen, easily administered, engaging and relevant tools may assist therapists to initially "engage-with" assessment. A highly individualized approach may assist therapists to progress from "I don't" to "I do", while concurrent organisation-wide adjustments that address gaps in opportunity, expectation, and efficient systems $[73,74]$ and promotion of assessment value among families are likely to be important for embedding assessment use to the "We do" level, where assessment is therapy and "just what you do."

\section{Implications for future research}

Future research is needed to validate the framework of the Cultural Cone for evidence-based assessment against existing tools and across other paediatric settings and contexts, and to investigate its potential clinical application in classifying use behaviour and designing interventions to increase assessment use. Consideration of assessment tool characteristics, in terms of capacity to engage therapists in assessment for children and families, is also warranted. Further research into the experiences and benefits of evidence-based assessment use in optimizing meaningful outcomes for children and families, is also needed.

\section{Limitations}

The study design enabled an in-depth exploration of allied health practitioners' assessment use and the development of a conceptual framework, but this exploratory study draws evidence from a limited number of settings within one cultural context. Therapists interviewed came to this study 
with similar experiences and understandings of evidence-based practice through professional education and training programmes. This may limit the transferability and applicability of these findings to settings where the concepts of evidence-based health care have been introduced more recently.

\section{Conclusions}

Therapists' use of assessment tools for children with cerebral palsy and their families in the clinical context is complex. Therapists' experiences of evidence-based assessments can be represented through the Cultural Cone framework which conceptualizes assessment use on a behavioural continuum of; I don't, I can't, I try, I do, We do. Motivation to use evidence-based assessments appears related to organisational expectation and support systems, therapist perceived satisfaction with assessment, affinity for research and dedication of time, along with family and child involvement with the assessment process. Promoting the use of 'any old assessment tool' however is not enough. Tools that are fun and engaging, add value to goal setting and communication with parents and children, and positively support the therapeutic relationship are more likely to be used.

Consistent with previous studies, low levels of assessment use overall were identified in this study. To address this, the Cultural Cone framework advocates knowledge translation interventions that firstly identify the relative strengths of the Cultural Cone elements, and then employ individualized evidence-based behaviour change techniques and organisational supports related to the therapist's context. This may spur a conceptual shift towards "assessment as therapy" and help address the low level and scope of assessments used generally across some paediatric rehabilitation settings.

\section{Acknowledgements}

This project was completed within the 'Cerebral Palsy Check Up: Providing the best service at the best time' project which was funded by the Australian National Health and Medical Research Council (APP1055278). We would also like to thank research assistants, Alice Ames and Mahek Dudhwala, for their assistance with data management, Karen Roberts and Lachlan Stewart for providing their respective expertise in group facilitation and graphic design, and Peter Rosenbaum and Mats Granlund for their informed perspectives in the formative stages of the study. Bridget O'Connor has received support through the Australian Government Research Training Program for her Masters of Philosophy programme and is a recipient Allied Health Postgraduate Scholarship awarded under the Nursing and Allied Health Scholarship and Support Scheme (NAHSSS) funded by the Commonwealth 
Department of Health (DoH) and administered by Services for Australian Rural and Remote Allied Health (SARRAH).

\section{Declaration of Interest}

The authors state that they have no interests which might be perceived as posing a conflict or bias.

Table 1: Organisational profiles

\begin{tabular}{l|cc} 
Characteristic & Organisation A & Organisation B \\
\hline Number of sites & & 1 \\
Centre & 0 & 0 \\
Early Childhood & 6 & 0 \\
School & 2 & Multi-disciplinary \& \\
Service model & Trans-disciplinary \& & Centre based \\
Funding source & Educational & Philanthropic 90\% \\
& Government 76\% & \\
Total Staff (no./EFT) & Other 24\% & $12 / 5.3$ \\
Occupational Therapists & $127 / 75.0$ & $2 / 0.8$ \\
Physiotherapists & $22 / 13.1$ & $5 / 2.0$ \\
Speech Pathologists & $16 / 11.1$ & $2 / 0.7$ \\
Total AHP & $26 / 13.0$ & $9 / 3.5$ \\
Other Allied Health & $64 / 37.2$ & 0 \\
Other Professional staff & $5 / 4.3$ & $1 / 0.4$ \\
Administrative staff & $14 / 8.7$ & $1 / 0.6$ \\
Senior Executives & NS & $1 / 0.8$ \\
Children & NS & \\
Age group & & El- School \\
Diagnoses & EI-School & CP and other \\
Total children in service (no.) & CP and other & 58 \\
Children with CP 3-<6 years & 630 & 25 \\
Children with CP 6-18 years & 20 & 26 \\
\hline
\end{tabular}

Legend: No., number; EFT, equivalent full time; AHP, allied health practitioner; NS, not specified; CP, cerebral palsy; El, early intervention; School-School aged (6-18years); Other Professional staff- e.g. recreational officers, team leaders. 
Box 1: TOPIC GUIDE: Allied health practitioner experiences of Evidence Based Practice and assessment

- What is your understanding of evidence-based practice?

- Considering the definition of EBP that I have just given you, what do you think is the relevance of evidence-based practice in your day-to-day work?

- What is your experience of using evidence-based assessment tools within your workplace?

- Can you expand on why you use, or don't use, evidence-based assessment tools with the children and families you see?

- What do you take into consideration when selecting an assessment tool for use with a child and family?

Table 2: Allied health practitioner participant characteristics

\begin{tabular}{|c|c|c|c|}
\hline AHP Characteristic & $\begin{array}{c}\text { Organisation A } \\
\qquad(n=47)\end{array}$ & $\begin{array}{l}\text { Organisation B } \\
\qquad(\mathrm{n}=8)\end{array}$ & $\begin{array}{c}\text { Combined } \\
n=55 \text { (\%) }\end{array}$ \\
\hline \multicolumn{4}{|l|}{ Discipline } \\
\hline Occupational Therapists & 16 & 2 & 18 \\
\hline Physiotherapists & 15 & 4 & 19 \\
\hline Speech Pathologists & 16 & 2 & 18 \\
\hline \multicolumn{4}{|l|}{ Years since graduation } \\
\hline$<5$ years & 10 & 0 & $10(18)$ \\
\hline$>5$ years & 37 & 8 & $45(82)$ \\
\hline \multicolumn{4}{|l|}{ Years in disability sector } \\
\hline$<5$ years & 16 & 4 & $20(36)$ \\
\hline$>5$ years & 31 & 4 & $35(64)$ \\
\hline \multicolumn{4}{|l|}{ Years with organization } \\
\hline$<5$ years & 29 & 6 & $35(64)$ \\
\hline$>5$ years & 18 & 2 & $20(36)$ \\
\hline \multicolumn{4}{|l|}{ Self-reported expertise level ${ }^{a}$} \\
\hline novice & 13 & 0 & $13(64)$ \\
\hline intermediate & 27 & 5 & $32(58)$ \\
\hline expert & 7 & 3 & $10(18)$ \\
\hline \multicolumn{4}{|l|}{ Further formal education } \\
\hline Degree level & 32 & 3 & $35(64)$ \\
\hline Post grad certificate or diploma & 12 & 3 & $15(27)$ \\
\hline Masters' degree & 2 & 2 & $4(7)$ \\
\hline Doctorate & 1 & 0 & $1(2)$ \\
\hline
\end{tabular}


Table 3: Child participant characteristics

\begin{tabular}{lccc} 
Characteristic & $\begin{array}{c}\text { Organisation A } \\
\mathrm{n}=21\end{array}$ & $\begin{array}{c}\text { Organisation B } \\
\mathrm{n}=23\end{array}$ & $\begin{array}{c}\text { Combined } \\
\mathrm{N}=44\end{array}$ \\
\hline $\begin{array}{c}\text { Age (years) at start } \\
\text { of extraction }\end{array}$ & & & \\
$2-<6$ & 4 & 15 & 14 \\
$6-11$ & 7 & 4 & 11 \\
$>11-18$ & 10 & 4 & 19 \\
Gender & & & \\
female & 6 & 14 & 20 \\
male & 15 & 9 & 24 \\
GMFCS Level & & & \\
I & 1 & 1 & 2 \\
II & 2 & 8 & 10 \\
III & 3 & 4 & 7 \\
IV & 5 & 7 & 12 \\
V & 10 & 3 & 13 \\
Distribution & & & \\
Bilateral & 17 & 17 & 34 \\
Unilateral & 1 & 4 & 5 \\
Unknown & 3 & 2 & 5 \\
\hline GMFCS: Gross Motor Function Classification System & &
\end{tabular}

GMFCS: Gross Motor Function Classification System 
Table 4: Frequency of assessment tool use (actual and self-reported) in each organization and combined: Actual number of children's files with completed individual assessments documented during audit period; and allied health practitioners self- reported rates of use of functional classification tools (Gross Motor Function Classification System, Manual Abilities Classification System or Communication Function Classification System), Canadian Occupational Performance Measure and Goal Attainment Scaling.

\begin{tabular}{|c|c|c|c|}
\hline & Organisation A & Organisation B & Combined \\
\hline Assessment tool*completed & $\begin{array}{c}\text { Child files } \\
n=21\end{array}$ & $\begin{array}{c}\begin{array}{c}\text { Child files } \\
n=23\end{array} \\
\end{array}$ & $(\%)$ \\
\hline GMFCS & 18 & 19 & $37 / 44(84)$ \\
\hline FMS & 18 & 12 & $30 / 44(69)$ \\
\hline $\mathrm{MACS}^{\mathrm{a}}$ & 0 & $9^{b}$ & $9 / 39(23)$ \\
\hline COPM & $0^{c}$ & $8^{d}$ & $8 / 38(21)$ \\
\hline Hip x-ray & 6 & 3 & $9 / 44(20)$ \\
\hline GMFM & $1^{\mathrm{c}}$ & $6^{d}$ & $7 / 38(18)$ \\
\hline Pain-tool undefined & 2 & 4 & $6 / 44(14)$ \\
\hline Goniometry-Lower Limb ${ }^{\mathrm{e}}$ & 3 & 3 & $6 / 44(14)$ \\
\hline Goniometry-Upper LImb ${ }^{f}$ & 3 & 2 & $5 / 44(11)$ \\
\hline ASAS & 1 & 1 & $2 / 44(5)$ \\
\hline $\mathrm{HAT}^{\mathrm{a}}$ & 1 & $1^{\mathrm{b}}$ & $2 / 39(5)$ \\
\hline CFCS & 0 & 2 & $2 / 44(5)$ \\
\hline PEDI & 0 & 1 & $1 / 44(2)$ \\
\hline DSS & 0 & 0 & $0 / 44(0)$ \\
\hline \multirow[t]{2}{*}{ mHouse } & 0 & 0 & $0 / 44(0)$ \\
\hline & AHPs & AHPs & AHPs \\
\hline Proportion of time tool* used & $\mathrm{n}=47$ & $\mathrm{n}=8$ & $n=55(\%)$ \\
\hline \multicolumn{4}{|l|}{ GMFCS, MACS or CFCS } \\
\hline $75-100 \%$ & 8 & 4 & $12(22 \%)$ \\
\hline $50-74 \%$ & 3 & 1 & $4(7 \%)$ \\
\hline $25-49 \%$ & 3 & 1 & $4(7 \%)$ \\
\hline $6-24 \%$ & 6 & 0 & $6(11 \%)$ \\
\hline $0-5 \%$ & 27 & 2 & $29(53 \%)$ \\
\hline \multicolumn{4}{|l|}{ COPM } \\
\hline $75-100 \%$ & 0 & 6 & $6(11 \%)$ \\
\hline $50-74 \%$ & 0 & 0 & $0(0 \%)$ \\
\hline $25-49 \%$ & 0 & 1 & $1(2 \%)$ \\
\hline $6-24 \%$ & 1 & 1 & $2(4 \%)$ \\
\hline $0-5 \%$ & 46 & 0 & $46(84 \%)$ \\
\hline \multicolumn{4}{|l|}{ GAS } \\
\hline $75-100 \%$ & 0 & 7 & $7(13 \%)$ \\
\hline $50-74 \%$ & 0 & 1 & $1(2 \%)$ \\
\hline $25-49 \%$ & 1 & 0 & $1(2 \%)$ \\
\hline $6-24 \%$ & 1 & 0 & $1(2 \%)$ \\
\hline $0-5 \%$ & 45 & 0 & $45(82 \%)$ \\
\hline
\end{tabular}

*Tool legend; ASAS, Australian Spasticity Assessment Scale; COPM, Canadian Occupational Performance Measure; CFCS, Communication Function Classification System; DSS, Dysphagia Severity Scale; FMS, Functional Mobility Scale GAS, Goal Attainment Scaling; GMFCS, Gross Motor Function Classification System; GMFM-66 or GMFM-88, Gross Motor Function Measure-66 or 88; HAT, Hypertonicity Assessment Tool; MACS, Manual Abilities Classification System; modHouse,

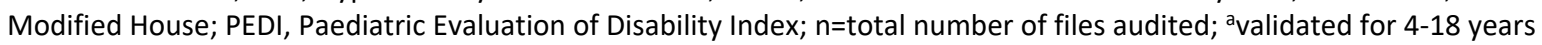


only. ${ }^{b} n=18$ as 5 children aged $<4$ years; ${ }^{c} n=18$ as unable to retrieve 3 archived files; ${ }^{d} n=20$ as unable to retrieve 3 archived files; ${ }^{e}$ wrist and elbow measures documented; fankle measure documented. AHPs; allied health practitioners.

Table 5: Number of therapists from high (HU), medium (MU) and low user (LU) AHP groups that rate a) organisational structure b) organizational resource $c$ ) therapists $d$ ) child and family and e) tools on a -5 to +5 Likert scale as either a support $(-5$ to -2$)$, ambivalent $(-1$ to +1$)$ or barrier $(+2$ to +5$)$, to routine assessment tool use.

\begin{tabular}{|c|c|c|c|c|}
\hline & & $\begin{array}{l}\text { Barrier } \\
(-5 \text { to }-2)\end{array}$ & $\begin{array}{l}\text { Ambivalent } \\
(-1 \text { to }+1)\end{array}$ & $\begin{array}{l}\text { Support } \\
(+2 \text { to }+5)\end{array}$ \\
\hline \multirow[t]{3}{*}{ a) Organizational Structures } & $\mathrm{HU} n=5$ & 0 & 0 & 5 \\
\hline & $\mathrm{MU} n=16$ & 5 & 3 & 8 \\
\hline & LU n=30 & 9 & 5 & 16 \\
\hline \multirow[t]{3}{*}{ b) Organizational Resources } & $\mathrm{HU} n=5$ & 0 & 0 & 5 \\
\hline & $\mathrm{MU} n=17$ & 7 & 3 & 7 \\
\hline & LU n=31 & 8 & 9 & 14 \\
\hline \multirow[t]{3}{*}{ c) Therapists } & $\mathrm{HU} n=5$ & 0 & 0 & 5 \\
\hline & $\mathrm{MU} n=17$ & 0 & 3 & 14 \\
\hline & LU n=31 & 0 & 13 & 18 \\
\hline \multirow[t]{3}{*}{ d) Child and Family } & $\mathrm{HU} n=4$ & 0 & 0 & 4 \\
\hline & $\mathrm{MU} n=17$ & 2 & 6 & 9 \\
\hline & LU n=31 & 2 & 12 & 17 \\
\hline \multirow[t]{3}{*}{ e) Tools } & $\mathrm{HU} n=5$ & 0 & 0 & 5 \\
\hline & $\mathrm{MU} n=17$ & 2 & 6 & 9 \\
\hline & LU n=31 & 1 & 13 & 17 \\
\hline
\end{tabular}

High user (HU): Uses tools consistently:

Reports use of Gross Motor Function Classification System, Manual Abilities Classification System or Communication Function Classification System, AND the Canadian Occupational Performance Measure and Goal Attainment Scaling, as more than $50 \%$ of the time.

Moderate user (MU): Uses some tools to some extent.

Reports use of Gross Motor Function Classification System, Manual Abilities Classification System or Communication Function Classification System, OR either the Canadian Occupational Performance Measure or Goal Attainment Scaling, or both, more than $25 \%$ of the time but High user criteria not met.

Low user (MU): Tools not used to any extent.

Reports use of Gross Motor Function Classification System, Manual Abilities Classification System or Communication Function Classification System, AND the Canadian Occupational Performance Measure and Goal Attainment Scaling, less than $25 \%$ of the time. 


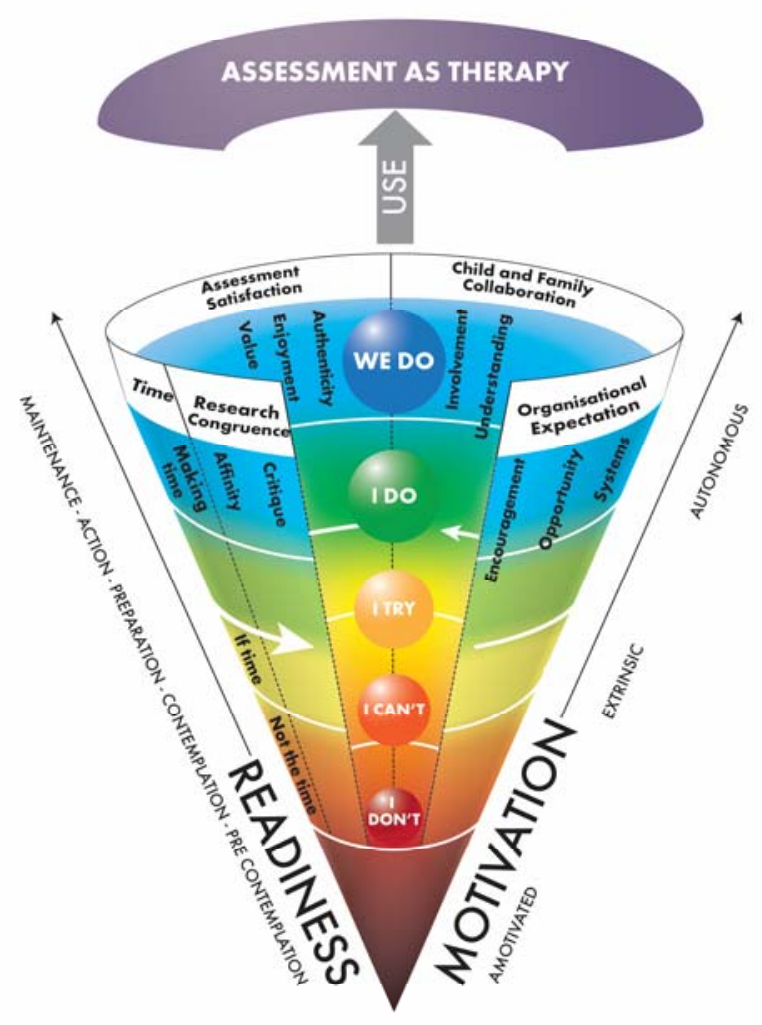

Figure 1: The "Cultural Cone" for evidence-based assessment behaviour. Themes and sub-themes are represented as cone segments whose interaction influences allied health practitioners' motivation and readiness -I don't, I can't, I try, I do, We do, and ultimate engagement in evidencebased assessment practice. 

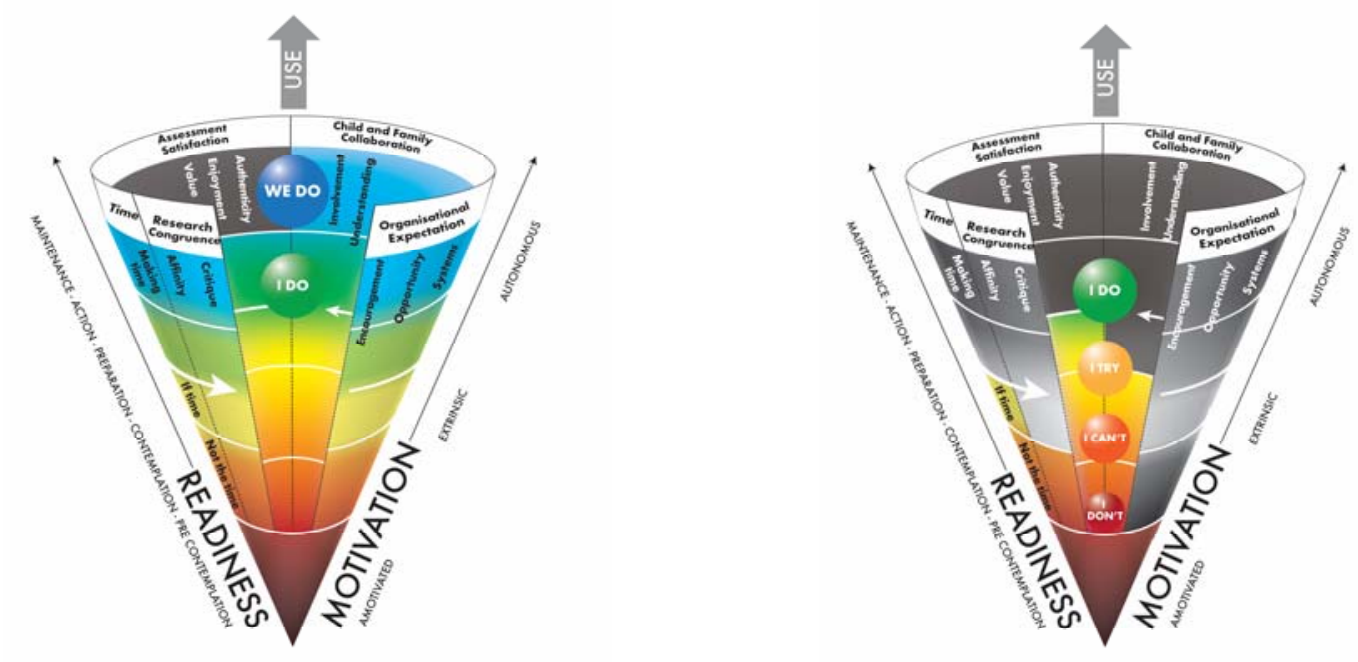

Figure 2 "Cultural Cone" for evidence-based assessment behaviour showing mapped performance for cone segments, motivation, and assessment use for a) Organisation A, and b) Organisation B.

\section{REFERENCES}

[1] Law M, Darrah J. Emerging therapy approaches: an emphasis on function. J Child Neurol. 2014;29:1101-1107.

[2] Wright FV, Majnemer A. The concept of a toolbox of outcome measures for children with cerebral palsy: why, what, and how to use? J Child Neurol. 2014;29:1055-1065.

[3] King G, Wright V, Russell DJ. Understanding paediatric rehabilitation therapists' lack of use of outcome measures. Disabil Rehabil. 2011;33:2662-2671.

[4] Law M, King G, Russell D, et al. Measuring outcomes in children's rehabilitation: a decision protocol. Arch Phys Med Rehabil. 1999;80:629-636.

[5] Green D. Translating evidence into practice. Dev Med Child Neurol. 2014;56:1132-1133.

[6] Duncan EA, Murray J. The barriers and facilitators to routine outcome measurement by allied health professionals in practice: a systematic review. BMC Health Serv Res.

2012;12:96-105.

[7] Grimmer-Somers K. Editorial-Incorporating research evidence into clinical practice decisions. Physiother Res Int. 2007;12:55-58.

[8] Brewer K, Pollock N, Wright FV. Addressing the challenges of collaborative goal setting with children and their families. Phys Occup Ther Pediatr. 2014;34:138-152.

[9] Majnemer A. Benefits of using outcome measures in pediatric rehabilitation. Phys Occup Ther Pediatr. 2010;30:165-167.

[10] Palisano RJ. A collaborative model of service delivery for children with movement disorders: a framework for evidence-based decision making. Phys Ther. 2006;86:1295-1305.

[11] Sackett DL, Rosenberg W, Gray J, et al. Evidence based medicine: what it is and what it isn't. Br Med J. 1996;312:71-72.

[12] Jette DU, Halbert J, Iverson C, et al. Use of standardized outcome measures in physical therapist practice: perceptions and applications. Phys Ther. 2009;89:125-135. 
[13] Stapleton T, McBrearty C. Use of standardised assessments and outcome measures among a sample of Irish occupational therapists working with adults with physical disabilities. $\mathrm{Br} \mathrm{J}$ Occup Ther. 2009;72:55-64.

[14] Piernik-Yoder B, Beck A. The use of standardized assessments in occupational therapy in the United States. Occup Ther Health Care. 2012;26:97-108.

[15] Copeland JM, Taylor WJ, Dean SG. Factors influencing the use of outcome measures for patients with low back pain: a survey of New Zealand physical therapists. Phys Ther. 2008;88:1492-1505.

[16] Saleh M, Korner-Bitensky N, Snider L, et al. Actual vs. Best practices for young children with cerebral palsy: A survey of paediatric occupational therapists and physical therapists in Quebec, Canada. Dev Neurorehabil. 2008;11:60-80.

[17] McConnell K, Johnston L, Kerr C. Therapy management of the upper limb in children with cerebral palsy: a cross-sectional survey. Dev Neurorehabil. 2012;15:343-350.

[18] Watson MR, Pennington L. Assessment and management of the communication difficulties of children with cerebral palsy: a UK survey of SLT practice. Int J Lang Commun Disord. 2015;50:241-259.

[19] O'Connor B, Kerr C, Shields N, et al. A systematic review of evidence-based assessment practices by allied health practitioners for children with cerebral palsy. Dev Med Child Neurol. 2016;58:332-347.

[20] Skeat J, Perry A. Exploring the implementation and use of outcome measurement in practice: a qualitative study. Int J Lang Commun Disord. 2008;43:110-125.

[21] Garland AF, Kruse M, Aarons GA. Clinicians and outcome measurement: what's the use? J Behav Health Serv Res. 2003;30:393-405.

[22] Colquhoun HL, Lamontagne M-E, Duncan EA, et al. A systematic review of interventions to increase the use of standardized outcome measures by rehabilitation professionals. Clin Rehabil. 2016;April 18:10.

[23] Käll I, Larsson MEH, Bernhardsson S. Use of outcome measures improved after a tailored implementation in primary care physiotherapy: a prospective, controlled study. J Eval Clin Pract. 2016;22:668-676.

[24] Forsetlund L, Bjørndal A, Rashidian A, et al. Continuing education meetings and workshops: effects on professional practice and health care outcomes. The Cochrane Library. 2009.

[25] Boaz A, Baeza J, Fraser A. Effective implementation of research into practice: an overview of systematic reviews of the health literature. BMC Res Notes. 2011;4:212.

[26] Baker R, Camosso-Stefinovic J, Gillies C, et al. Tailored interventions to overcome identified barriers to change: effects on professional practice and health care outcomes. Cochrane Database of Syst Rev. 2010; 4 CD005470.

[27] Grol R, Wensing M. What drives change? Barriers to and incentives for achieving evidencebased practice. Med J Aust. 2004;180:S57-60.

[28] Yano EM. The role of organizational research in implementing evidence-based practice: QUERI Series. Implement Sci. 2008;3:29-44.

[29] Nilsen P, Bernhardsson S. Towards evidence-based physiotherapy - research challenges and needs. J Physiother. 2013;59:143-144.

[30] Ryan R. Thoughts On The Genesis Of Self-Determination Theory. Am J Health Promot. 2013;27:TAHP-8.

[31] Prochaska JO, Redding C, Evers K. The transtheoretical model and stages of change. In: Glanz K, Rimer B, Lewis F, editors. Health Behavior and Health Education: Theory, Research, and Practice. 3rd ed: San Francisco: Jossey-Bass; 2008b.

[32] Prochaska JO, Norcross JC. Systems of psychotherapy : a transtheoretical analysis. 8th edition. ed. Belmont, CA: Brooks/Cole Cengage Learning; 2014. 
[33] Ryan RM, Deci EL. Intrinsic and Extrinsic Motivations: Classic Definitions and New Directions. Contemp Educ Psychol. 2000;25:54-67.

[34] Gale J, Skouteris H. Applied Topics in Health PsychologyHealth Coaching: Facilitating Health Behavior Change for Chronic Condition Prevention and Self-Management. Appl. Topics Health Psychol. 2012:15.

[35] Ryan RM, Deci EL. Self-determination theory and the facilitation of intrinsic motivation, social development, and well-being. Am Psychol. 2000;55:68-78.

[36] Polatajko HJ, Mandich A. Enabling occupation in children: The cognitive orientation to daily occupational performance (CO-OP) approach: JSTOR; 2004.

[37] Dannapfel P, Peolsson A, Nilsen P. What supports physiotherapists' use of research in clinical practice? A qualitative study in Sweden. Implementation Science. 2013;8:1-13.

[38] Johnson RB, Onwuegbuzie AJ, Turner LA. Toward a definition of mixed methods research. Journal of mixed methods research. 2007;1:112-133.

[39] Imms C, Novak I, Kerr C, et al. Improving allied health professionals' research implementation behaviours for children with cerebral palsy: protocol for a before-after study. Implement Sci. 2015;10:16.

[40] Morse JM, Niehaus L. Mixed method design : principles and procedures. Walnut Creek, California: Left Coast Press; 2009.

[41] Crotty M. The foundations of social research: Meaning and perspective in the research process. St Leonards, Australia: Allen \& Unwin; 1998.

[42] Estabrooks CA, Squires JE, Cummings GG, et al. Development and assessment of the Alberta Context Tool. BMC Health Serv Res. 2009;9:234.

[43] Peters $M$, Harmsen $M$, Laurant $M$, et al. Barriers to and facilitators for improvement of patient care. Nijmegen, the Netherlands: Centre for Quality of Care (WOK), Radboud University Nijmegen Medical Centre. 2002.

[44] Jung T, Scott T, Davies HT, et al. Instruments for exploring organizational culture: A review of the literature. Public Adm Rev. 2009;69:1087-1096.

[45] Chaudoir SR, Dugan AG, Barr C. Measuring factors affecting implementation of health innovations: a systematic review of structural, organizational, provider, patient, and innovation level measures. Implement Sci. 2013;8:22.

[46] Kerr C, Bowe S, Miyazaki K, et al. Psychometric properties of the 'Evidence Based Practice Competencies Questionnaire - Cerebral Palsy.' Phys Occup Ther Pediatr. Under Review.

[47] Rivard L, Russell D, Roxborough L, et al. Promoting the Use of Measurement Tools in Practice: A Mixed-Methods Study of the Activities and Experiences of Physical Therapist Knowledge Brokers. Phys Ther. 2010;90:1580-1590.

[48] Fleuren M, Wiefferink K, Paulussen T. Determinants of innovation within health care organizations. Int J Qual Health Care. 2004;16:107-123.

[49] Hägglund G, Alriksson-Schmidt A, Lauge-Pedersen $\mathrm{H}$, et al. Prevention of dislocation of the hip in children with cerebral palsy: 20-year results of a population-based prevention programme. Bone \& Joint Journal. 2014;96-B:1546-1552.

[50] World Health Organization. International Classification of Functioning, Disability and Health : Children and Youth Version (ICF-CY). Geneva: World Health Organization (WHO); 2007.

[51] Vargus-Adams JN, Martin LK. Domains of importance for parents, medical professionals and youth with cerebral palsy considering treatment outcomes. Child Care Health Dev.

2011;37:276-281. 
[52] Thorne S, Kirkham SR, MacDonald-Emes J. Focus on qualitative methods. Interpretive description: a noncategorical qualitative alternative for developing nursing knowledge. Res Nurs Health. 1997;20:169-177.

[53] Thorne S, Kirkham SR, O'Flynn-Magee K. The Analytic Challenge in Interpretive Description. Int J Qual Methods. 2004;3:1-21.

[54] Thorne SE. Interpretive description. Walnut Creek, CA: Left Coast Press; 2008.

[55] King G, Currie M, Bartlett DJ, et al. The development of expertise in pediatric rehabilitation therapists: Changes in approach, self-knowledge, and use of enabling and customizing strategies. Dev Neurorehabil. 2007;10:223-240.

[56] Bright FAS, Kayes NM, Worrall L, et al. A conceptual review of engagement in healthcare and rehabilitation. Disabil Rehabil. 2015;37:643-654.

[57] King. H. The AMPS and clinical practice (Letter). Br J Occup Ther Health Care. 2000;63 561.

[58] Narayanan U. Making a difference ... Are we? Dev Med Child Neurol. 2016;58:888-889.

[59] Wilson A, Kavanaugh A, Moher R, et al. Development and pilot testing of the Challenge module: A proposed adjunct to the Gross Motor Function Measure for high-functioning children with cerebral palsy. Phys Occup Ther Pediatr. 2011;31:135-149.

[60] Mistry B, Gibson B, Wright V. Development of an engagement guideline for the Challenge (abstract). Dev Med Child Neurol. 2016;58(S5):16.

[61] Petersson C, Huus K, Åkesson K, et al. Children's experiences about a structured assessment of health-related quality of life during a patient encounter. Child Care Health Dev. 2016;42:424-432.

[62] Tam C, Teachman G, Wright V. Paediatric application of individualised client-centred outcome measures: A literature review. Br J Occup Ther. 2008;71:286-296.

[63] Colquhoun HL, Letts LJ, Law MC, et al. Administration of the Canadian Occupational Performance Measure: Effect on practice. Can J Occup Ther. 2012;79:120-12

[64] Majnemer A, editor. Measures for children with developmental disability : an ICF-CY approach. London: Mac Keith Press; 2012.

[65] Kay TM, Myers AM, Huijbregts MP. How far have we come since 1992? A comparative survey of physiotherapists' use of outcome measures. Physiother Can. 2001;53:268-275.

[66] Wallen M, Hoare B. Can goal setting be isolated from activity-focused intervention in cerebral palsy? Dev Med Child Neurol. 2014;56:503.

[67] Brogren Carlberg E, Löwing K. Does goal setting in activity-focused interventions for children with cerebral palsy influence treatment outcome? Dev Med Child Neurol. 2013;55:47-54.

[68] Wawrzuta J, Willoughby KL, Molesworth C, et al. Hip health at skeletal maturity: a population-based study of young adults with cerebral palsy. Dev Med Child Neurol. 2016;58:1273-1280.

[69] Markland D, Ryan RM, Tobin VJ, et al. Motivational interviewing and self-determination theory. J Soc Clin Psychol. 2005;24:811-831.

[70] Deci EL, Ryan RM. The "What" and "Why" of Goal Pursuits: Human Needs and the SelfDetermination of Behavior. Psychol Inq. 2000;11:227-268.

[71] Poulsen AA, Rodger S, Ziviani JM. Understanding children's motivation from a selfdetermination theoretical perspective: Implications for practice. Aust Occup Ther J. 2006;53:78-86.

[72] Friederichs SA, Oenema A, Bolman C, et al. Motivational interviewing and self-determination theory in a web-based computer tailored physical activity intervention: A randomized controlled trial. Psychol Health. 2016:1-24.

[73] Lowes LP, Noritz GH, Newmeyer A, et al. 'Learn From Every Patient': implementation and early results of a learning health system. Dev Med Child Neurol. 2016;59:183-191.

[74] Oeffinger D. Use of standardized outcome measures should be common place in the clinical care of children with cerebral palsy: why isn't it? Dev Med Child Neurol. 2016;58:321. 
